\title{
Entre las tipologías políticas y los procesos sociales: elementos para el análisis situacional de los liderazgos indígenas en una frontera colonial ${ }^{1}$
}

Guillermo Wilde

Resumen: Este artículo propone un modelo de análisis del liderazgo indígena basado en la reconstrucción de situaciones sociales. Tomando como caso el contexto de las reducciones jesuíticas de guaraníes se analizan las transformaciones del poder nativo a lo largo del tiempo. La primera parte describe la formación de la nueva organización política enfatizando las relaciones existentes entre la etnogénesis de la misión y la institución de la figura política de los líderes indígenas - los caciques y los cabildantes - que participan de su gobierno. La segunda parte analiza el desenvolvimiento de los líderes indígenas en tres situaciones críticas de la historia de las reducciones: la guerra guaranítica, la expulsión de los jesuitas y el período postjesuítico. Cada una de estas situaciones constituye una trama compleja de reacomodamiento del poder en la que participan las autoridades nativas, en el marco más amplio del reordenamiento del mapa político e institucional de las reducciones y el Estado colonial.

Palabras clave: Liderazgo indígena. Cabildos. Guaraníes. Reducciones jesuíticas.

Las organizaciones políticas indígenas han sido una preocupación central de la antropología desde sus orígenes. ${ }^{2}$ De un interés inicial por la cuestión del orden en las sociedades primitivas, los trabajos clásicos gradualmente pasaron a establecer refinadas tipologías de

* Professor da UNSAN/Pesquisador CONICET. 
organización socio-política dentro de un esquema evolutivo que iba desde los sistemas más simples y "cerrados" a los más complejos, "abiertos" y "dinámicos". Estos últimos eran generalmente identificados con la figura del "estado", organización a la que se llegaba previo paso por formaciones como la "banda", la "tribu" y la "jefatura" (LLOBERA, 1985). En dicho esquema, el "liderazgo" se definía como una forma de ejercicio del poder correspondiente a los grupos locales del tipo "tribu", es decir, sociedades carentes por definición de centralización y jerarquías políticas.

Este tipo de enfoque, dominante durante buena parte de la antropología del siglo XX, sin duda tuvo la virtud - al menos en sus formulaciones más rigurosas - de abstraer rasgos a partir de casos particulares, facilitando la comparación o permitiendo indagar sobre el funcionamiento interno de cada organización en términos de "sistema". De este modo podían incorporarse a una misma grilla gran diversidad de casos provenientes de las regiones más distantes y los tiempos más remotos. En dicho abordaje las "funciones" de cada tipo de organización eran abstraídas de los contextos concretos para obtener tipos comparables. ${ }^{3}$

Más allá de su utilidad, estos modelos de carácter abstracto y estático, resultan limitados para el análisis de dos aspectos: a) los procesos de cambio social y político en sociedades particulares, y b) el significado de la acción política individual y colectiva en contextos específicos. El abordaje que aquí propongo tiene como preocupación central recuperar esos dos aspectos para abordar situaciones de construcción de liderazgo indígena desde un punto de vista histórico y procesual. Dicho análisis pone entre paréntesis la pregunta sobre las funciones del líder para centrarse en el modo como las figuras nativas de poder se construyen o instituyen en situaciones y procesos históricos concretos. Esto no significa negar el peso de las tradiciones culturales y políticas sino, por el contrario, situar su producción y variaciones en el acontecimiento. A partir de un caso particular, intentaré mostrar el modo como las figuras del poder nativo se acomodan y reacomodan a situaciones concretas, poniendo en juego elementos o recursos de diferente tipo, en relaciones e interacciones sociales de distinta escala. ${ }^{4}$ 
En el contexto elegido interactúa un sector de la sociedad colonial, los sacerdotes de la Compañía de Jesús, y una diversidad de grupos genéricamente reconocidos como "guaraníes", que habitaron en una amplia región de la América Meridional, incorporados a pueblos de reducción durante el período comprendido entre 1609 y 1768. La consideración de un período tan prolongado de tiempo permite, por un lado, indagar sobre una modalidad específica de introducción del poder colonial, con sus instituciones características, entre los indígenas de las Tierras Bajas Sudamericanas. Por otro lado, estudiar la formación de una organización política particular, las reducciones, como el resultado directo de dicha interacción colonial. Es importante señalar que la construcción del poder en estos espacios resulta de un proceso constante de actualizaciones prácticas, acomodaciones y reacomodaciones, en las cuales se pierde efectivamente la atribución que separa lo "propiamente nativo o autóctono", comúnmente asociado a un "tiempo anterior" (prehispánico), y lo "colonial o impuesto", como si se tratara de dos lados separados. En este sentido, no hay una imagen del indígena que pueda salir unívoca y diferenciada como totalidad, pues se forma en un proceso complejo de interacciones coloniales, cuya reconstrucción revela un universo múltiple, heterogéneo y a veces ambiguo de acción. ${ }^{5}$

Parto de la premisa de que, en el caso en cuestión, los actores no están movidos por una tradición intrínseca que pueda delimitarse en bloque (un ethos o una cultura), ni tampoco por una imposición totalmente externa. La lógica de la acción debe indagarse teniendo en cuenta tanto los procesos como las situaciones sociales, instancias en las que es posible abordar los cambios de relaciones de fuerza, las reformulaciones prácticas y revaloraciones de sentido. Distintos individuos pueden llevar consigo una serie de valores similares, pero la singularidad de la acción (diferenciada) está en última instancia determinada por trayectorias y contextos que deben estudiarse de manera intensiva. Todos los elementos en cuestión actúan en el mismo momento de interacción. En otras palabras, los indígenas entran a disputar códigos y valores de referencia en el marco del régimen colonial, como recursos apropiados para los nuevos juegos de poder en los que participan activamente. En este sentido, el universo de posibles o los márgenes de acción, constituyen la estructura 
presente del régimen colonial; un campo de configuración de valores y relaciones de poder en disputa en el que participan actores indígenas y no-indígenas. ${ }^{6}$

Este artículo se divide en dos partes. La primera describe la formación de la organización política de las reducciones guaraníes enfatizando las relaciones existentes entre la etnogénesis de la misión y la institución de la figura política de los líderes indígenas - los "caciques" y los cabildantes - que participan de su gobierno. La segunda parte considera el desenvolvimiento de esos líderes en tres situaciones críticas de la historia de las reducciones: la guerra guaranítica, la expulsión de los jesuitas y el período postjesuítico. ${ }^{7}$ Cada una de estas situaciones constituye una trama compleja de reacomodamiento del poder en la que participan las autoridades nativas, en el marco más amplio del reordenamiento del mapa político e institucional de las reducciones y el estado colonial.

\section{Liderazgo y Etnogénesis}

$\mathrm{El}$ análisis de las figuras indígenas de autoridad en las reducciones no puede separarse del proceso mismo de conformación del régimen misional en las fronteras sudamericanas durante más de una centuria. Entre 1609 y 1707 los jesuitas fundaron alrededor de cincuenta pueblos en las regiones conocidas como Guairá, AcarayIguazú, Itatín y Tape, relocalizando y concentrando población indígena de diferentes orígenes. La acción jesuita ya contaba con el antecedente franciscano, que había introducido los "pueblos-tava", sujetos a regímenes de trabajo de encomienda (NECKER, 1990).

El cuadro que las crónicas jesuíticas hacen de las instituciones nativas de poder en las etapas iniciales del contacto debe ser tomado con cautela, pues no solo estaba filtrado de preconceptos sino que no refleja suficientemente el dinamismo de las sociedades indígenas. ${ }^{8}$ De acuerdo a las crónicas del contacto, los grupos indígenas que se incorporaron a las reducciones se caracterizaban por fuertes tendencias hacia a la segmentación política y resistían a la centralización del poder. Según informan los jesuitas, para la llegada de los españoles, los guaraníes estaban organizados socialmente 
en familias extensas o "linajes" llamados teyý que contaban de 40 a 90 hombres (probablemente hasta 300 personas) y que residían en pequeños grupos diseminados en grandes casas o malocas. El teyý constituía la unidad económica y política básica caracterizada por un importante grado de autonomía. En un nivel superior, informa el jesuita Ruiz de Montoya, se encontraba el amunda, que designaba a la aldea reuniendo una o varias familias extensas. Un tercer nivel estaba representado por el teko'a que podía ser una aldea o un conjunto de aldeas. Resulta difícil distinguir amunda y teko'a ya que con frecuencia se confunden en las fuentes. Por último Ruiz de Montoya menciona la guara, una unidad regional constituida por un conjunto de teko 'a. Este último nivel es traducido por el jesuita como "patria", "país", "provincia" o "región", aunque en sentido estricto significa "procedente de" (RUIZ DE MONTOYA, [163940] 1876). A la cabeza de cada uno de estos niveles de organización social había un líder (ruvicha o mburuvicha) que mantenía relaciones (de alianza o conflicto) con sus pares, de lo que dependía en buena medida el aumento o disminución de su prestigio. La reciprocidad y el parentesco eran los vínculos centrales entre las diversas unidades socio-políticas (SUSNIK, 1965, p. 198). ' La caracterización de Ruiz de Montoya no debe tomarse como un axioma, en la medida que no se mantiene en los documentos jesuíticos a lo largo del tiempo. En las descripciones tienden a prevalecer términos como "parcialidad", "cacicazgo" y "nación", como denominación de los colectivos incorporados. A juzgar por las fuentes jesuíticas, es probable que la estructura básica del teyý o familia extensa prevaleciera dentro de las reducciones en la forma de la parcialidad o el cacicazgo. Eran los jefes de dichas familias, los que negociaban con los sacerdotes su incorporación a los nuevos pueblos, a cambio de protección y privilegios dentro de la nueva formación colonial.

La instauración del régimen misional conllevó un verdadero proceso de etnogénesis y etnificación (WILDE, 2009a; 2011). Con el objeto de evitar el contacto de la población indígena con la española, los religiosos defendieron acérrimamente una política de segregación residencial mantenimiento una versión estandarizada de la lengua nativa, el guaraní de la reducción (MELIÁ, 2003). La población que aceptaba la conversión era trasladada a pueblos de 
reducción que respondían a los lineamientos políticos, económicos y espaciales de la legislación indiana. Uno de ellos era la formación de un gobierno municipal autónomo. A los líderes indígenas que aceptaban reducirse, denominados "caciques", se les otorgaba una serie de cargos administrativos, eclesiásticos y militares según sus condiciones, colaborando con los jesuitas en la administración de los pueblos. Con el paso de las décadas y la progresiva instalación de una educación formal de las elites, se fue formando en los pueblos una nueva "burocracia" indígena que no coincidía directamente con la organización cacical instalada, ocasionando frecuentes conflictos en los mecanismos de legitimación. ${ }^{10}$

La organización político institucional de los pueblos de reducción dependía en gran medida del cabildo, exigido en todos los territorios de la corona española. De acuerdo a la legislación indiana, esa institución debía estar compuesta por diversos cargos que debían renovarse cada año (corregidor, teniente de corregidor, alcaldes ordinarios de primer y segundo voto, alcaldes de hermandad, alférez real, regidores, alguaciles mayores, mayordomo y secretario). Los cabildos indígenas representaron uno de los ámbitos por excelencia para la institución de un poder político estático y centralizado. Para su instalación, los jesuitas apelaron a la lengua indígena estableciendo nombres que designaran figuras de poder antes inexistentes. Algunos de esos términos son referidos en el conocido Tesoro de la Lengua Guaraní de Ruiz de Montoya. Llamaron al corregidor poroquaitara, "el que manda lo que debe hacerse"; cabildoiguara a los regidores ("los que pertenecen al cabildo o concejo"); El término ibira, utilizado para referir al bastón de mando otorgado, se encontraba en la raíz de los nombres del alcalde y el alguacil, respectivamente ibirarucu, y ibirayara. Se llamaba al alférez real aobebé rerequara ("el que cuida del estandarte"); y quatiaapobara al escribano ("el que escribe"). Cada cargo iba acompañado del correspondiente símbolo y emblema de poder, que resaltaba visualmente las jerarquías sociales y políticas. ${ }^{11}$ En este proceso de reconfiguración del poder nativo tuvo gran relevancia la incorporación de nuevas tecnologías, como la escritura, enseñada por los jesuitas a una importante fracción de la elite indígena (NEUMANN, 2007; 2008; 2011). No hace falta decir que los mismos indígenas se apropian de los recursos simbólicos 
y materiales incorporados con el mismo régimen y los emplean en sus juegos de poder. La lógica de estas apropiaciones aún debe estudiarse en profundidad. Aún desconocemos qué representaban los nuevos símbolos para los indígenas (por ejemplo, vestimentas y varas de mando), más allá de los valores que la organización colonial les atribuía, en otras palabras, el lugar que los mismos pasaron a ocupar en las dinámicas cosmológicas preexistentes.

Para el siglo XVIII ya se encontraba instalada en las reducciones una separación entre la "burocracia" indígena con poder de policía, que se aglutinada en el cabildo y que era afín a los intereses evangélicos y administrativos de los jesuitas, y la autoridad de los "caciques", nombre atribuido a los jefes de familia que se incorporaban a las misiones junto a sus parientes o miembros de cacicazgo, frecuentemente denominados "vasallos", destinados a cumplir un importante rol en al reproducción económica y social de los pueblos. La autoridad de los "caciques" se sustentada en mecanismos reciprocitarios y de parentesco que permitían mantener cierto grado de cohesión entre los individuos incorporados. Branislava Susnik relaciona respectivamente a estos sectores con el "mando" o poder coercitivo y el "prestigio" o poder de consenso. La "burocracia" cabildante se dividía entre los encargados de controlar las faenas colectivas ("los que mandan") y la gente de "oficios y artesanía" ("los que conocen"). Se trataba de grupos socialmente diferenciados y con privilegios que en promedio constituían el nada despreciable porcentaje del 10 por ciento de la población (SUSNIK, 1990-1991, p. 122). Este esquema adquirirá fuerza en el ámbito de las reducciones con el paso de las décadas. Si bien la mayor parte de los líderes se ocupaba de supervisar el reclutamiento de los miembros de su familia para las faenas colectivas, varios de ellos, los llamados "principales", formaban parte del cabildo, siendo el más importante el que ocupaba el cargo de corregidor. Las investigaciones recientes de Kazuhiza Takeda sobre los padrones de indios en todas las reducciones demuestran que, con el paso del tiempo, el poder de los caciques fue quedando limitado a la administración de las "parcialidades" o "cacicazgos", mientras eran progresivamente desplazados de los cargos de cabildo y milicias (TAKEDA, 2010).

Este fenómeno quizás explique que, una vez consolidada la estructura política de los pueblos, comenzaran a hacerse visibles 
serias disputas entre los caciques y los cabildantes. No todos los corregidores designados eran caciques, ni todos los caciques se convertían en cabildantes. De modo que ambos tipos de autoridad se superpusieron de manera tensa a lo largo de todo el período de existencia de las misiones. Por otra parte, los jesuitas, siguiendo la legislación indiana, impusieron la sucesión de cacicazgos de padres a hijos por sangre. Así creaban un sistema estable y controlable de autoridades buscando vehículos institucionales (el cabildo) para la definición de legitimidades.

La "sucesión” del cacicazgo parece haber sido objeto de conflicto una vez instalado el sistema jerárquico y centralizado. Así lo revela un episodio en el que se enfrentan la elite indígena y un cura jesuita por la sucesión del cacicazgo de Don Abraham Apuy, ocurrido en el pueblo de Santo Tomé, en 1763 (WILDE, 2006; 2009). Sacerdote y cabildo indígena se enfrentan ante los superiores a propósito de la designación del sucesor. Mientras el primero sostenía, basado en la legislación, que la sucesión correspondía a una india llamada Martina Cherocae, los segundos hacían valer su derecho "tradicional" de legitimar a un sujeto (Athanasio Mbayari) considerado con mayor prestigio, o simplemente más cercano al grupo de poder, aunque no continuara una línea de sucesión directa. Más allá de la solución del caso, el conflicto pone en evidencia la superposición, e incluso la ambigüedad del ejercicio, de dos modalidades contradictorias de legitimación, una basada en las relaciones y atributos personales y otra en la sucesión por sangre.

Después de la expulsión de los jesuitas en 1768, la primera modalidad se convierte en la más común a juzgar por las numerosas quejas que se manifiestan en los documentos. Existen indicios de que en este período se produjo un incremento notable en las ambiciones de varios indígenas. Los indios "están muy creidos" escribe un funcionario en el pueblo de San Miguel en 1769 y Gonzalo de Doblas, en su Memoria Histórica, describe esas ambiciones del siguiente modo:

[...] [t]odos ellos son inclinados á mandar y anhelar por cualesquiera empleo y ocupación por despreciable que sea; y procuran desempeñarlo el tiempo que les dura, y manifiestan mucho sentimiento cuando fuera de tiempo, y 
por algún motivo que hayan dado, se les priva del empleo, teniéndolo por mengua y deshonor: sienten asimismo las palabras injuriosas, y el estar en desgracia del que los manda; de modo que en cometiendo alguna falta, aunque sean los muchachos, desean que 1uego los azoten y no los maltraten de palabras, para volver á la gracia de sus superiores. Es en ellos circunstancia apreciable para emplearlos la elocuencia y persuasiva, y tienen en poco al que le falta esta prerrogativa, aunque tenga otras recomendables: se precian mucho de vergonzosos y pundonorosos, pero por falta de educación y de ideas no saben usar rectamente de estas virtudes. En ellos no es deshonor el emplearse en oficios ruines, aun los que acaban de obtener los empleos más honoríficos, porque no conocen ni distinguen lo noble de lo uno, ni lo ruin de lo otro. Tampoco es deshonor el que los azoten cada día, bien es que si esto lo fuera, muy, raro sería el que no se considerara deshonrado. (DOBLAS, [1785] 1836-1937, p. 11-12).

En la construcción del poder político de la reducción no era de importancia menor la instalación de una estructura militar. Ya desde el siglo XVII la situación fronteriza de las misiones había hecho de la actividad militar un aspecto constitutivo de la pertenencia guaraní misionera. Esto no implica adherir a la idea esencialista de una continuidad del "ethos guerrero" indígena sino, por el contrario, atribuir un valor histórico singular a la participación indígena en la organización militar colonial. Si bien muy probablemente las tradiciones belicistas previas existieron, una evaluación en términos históricos implica considerar este aspecto de la vida misional como una particularidad de la formación jesuítico-guaraní que reforzaba identificaciones al nivel del cacicazgo, la compañía militar o el poblado. En efecto, la historia de una reducción o de una familia, podía construirse sobre la base de su historia militar (triunfo en una batalla, servicios a la corona, asistencia a otras reducciones), reforzando así rasgos de singularidad que se manifestaban en los símbolos, las insignias y los relatos orales (o escritos) trasmitidos de una generación a la siguiente.

En un primer momento las milicias defendieron a los pueblos de los ataques paulistas. Más tarde contribuyeron a la defensa de 
los territorios del monarca católico. Los conflictos que dominaron la región fueron sedimentando en cada pueblo guaraní una historia singular ligada a sus hazañas militares, sus figuras de prestigio y sus servicios al monarca católico. Podría decirse que el aspecto militar, junto con el político administrativo y el religioso constituían los cimientos del régimen misional.

Los gobernadores de Asunción y Buenos Aires solían otorgar títulos militares a los caciques guaraníes que colaboraban en la lucha contra los enemigos de la corona. Según afirmaba Lorenzana, la figura de "capitán" no fue fácil de introducir pues los indios no estaban acostumbrados a reconocer otro superior que el cacique. La distinción de "capitán general de guerra y justicia mayor de las reducciones" también implicaba hacer cumplir a los indios con la doctrina "no consintiendo estén casados infieles con cristianos ni cristianos con infieles, ni amancebados, ni que tengan juntas ni borracheras y hagan sus sementeras y estén con buena policía y ejemplo en servicio de Dios" (SALINAS, 2006, p. 272). Ya desde el siglo XVII existen datos específicos sobre nombramientos militares de caciques de las misiones por parte de los gobernadores. ${ }^{12}$ Como sea, Kazuhiza Takeda muestra, a partir de las listas encontradas en diversos archivos, que los caciques fueron gradualmente desplazados de los cargos de milicias, especialmente a partir del siglo XVIII, en que tales organizaciones se expandieron al servicio de la corona española (TAKEDA, 2010).

En síntesis, el funcionamiento político de las reducciones se asentaba sobre la acción coordinada de los jesuitas con la elite indígena que ocupaba cargos de tipo político-administrativo, eclesiástico y militar, dentro de una estructura que daba preeminencia a la descendencia por "linajes" organizados a partir de la figura de los "cacicazgos" incorporados, los cuales variaban en dimensiones y capacidades de acción. A su vez, la reducción constituía una formación territorial concreta, caracterizada por un tipo particular de organización institucional y económica (municipal), segregada del mundo español desde el punto de vista espacial, cultural y lingüístico. ${ }^{13}$ Sin embargo, esto no impidió que los indios reducidos mantuvieran contactos frecuentes con la población indígena no reducida circunvecina, los llamados "indios infieles" ("charrúas", "minuanes", 
“yaros”, "guenoas", “mbayas”, “cainguás”, “abipones”, etc.) quienes, además de ser objeto de clasificaciones étnicas y políticas específicas de incorporación a la vida cristiana por parte de la administración jesuítica, conservaban lazos de parentesco con los indios cristianos (WILDE, 2009; GARCIA, 2009; BRACCO, 2004).

En suma, las formas nativas de poder emergentes y las disputas derivadas de sus divisiones son parte del mismo proceso de etnogénesis de la misión, montado, a su vez sobre la fragmentación de las formas previas de organización sociopolítica. Dicho de otro modo, lo que podríamos identificar como lógicas indígenas de la acción no es la expresión de una "esencia nativa", sino el resultado de un proceso en el cual "lo indígena", aunque aparezca ocupando un lugar especial en el discurso nativo e institucional, no constituye una identidad unívoca sino una confluencia de niveles y trayectorias inscriptas social e históricamente. En ese sentido, la tradición sociocultural y política que definen las reducciones es el resultado de una relación colonial en movimiento. La acción indígena no expresa contenidos culturales monolíticos, sino el producto de un largo período de resistencias, negociaciones y apropiaciones no solo con el mundo colonial sino de los indígenas entre sí. Entonces, no importa tanto establecer los contenidos o elementos culturales prístinos que habrían conformado esa acción social como inferir sentidos inscriptos en relaciones sociales e históricas. De allí la importancia de circunscribir eventos o situaciones críticas en los que se actualiza la autoridad y se desenvuelve la acción.

\section{Anàlisis de tres situaciones sociales}

Las definiciones metodológicas previas hacen imperativo describir contextos de interacción en el mayor detalle que sea posible, evitando aplicar fórmulas predefinidas de análisis. Los contextos o "situaciones sociales" pueden definirse como escenarios en los que se desenvuelven formas variadas de interacción social y se pueden identificar las opciones de los actores en el mundo social, interpretando el sentido y las lógicas de sus acciones. ${ }^{14}$ 
La siguiente sección propone un análisis de tres situaciones sociales conflictivas en las que el liderazgo indígena de la reducción se actualiza. La reconstrucción de dichas situaciones permite apreciar el modo como los indígenas instrumentan recursos disponibles para definir y redefinir alianzas e identidades políticas. Tal dinámica se produce en el marco del mismo régimen misional, entendido como una configuración dinámica que los mismos indígenas como actores han contribuido a definir. En tal sentido, los "caciques" y los "cabildantes", dos categorías socio-políticas centrales en el régimen misional, ocupan roles protagónicos en las disputas de autoridad.

\section{Situación social 1: el gran levantamiento}

Pocos años después de la firma del Tratado de Madrid (1750), que estipulaba el traslado de la población guaraní de siete reducciones al oeste del río Uruguay se inició una sublevación general de los indios que culminó con el conflicto conocido como "guerra guaranitica”. En 1752, algunos caciques del pueblo de San Nicolás empezaron a conspirar contra el cura del pueblo en oposición al traslado, y de ese pueblo se expandió el motín a otras seis reducciones. Los jesuitas pronto se encontraron frente a un gran alboroto: varios indios con oficio público querían dejar sus bastones de mando en medio de la plaza al son de tambores, y matar al corregidor, alcaldes, secretario y cualquier persona leal a los religiosos.

Durante los años que duró el gran levantamiento, que culminó en 1756, los rebeldes usaron todos los recursos a su disposición para coordinar actividades bélicas, evitar el avance de las tropas españolas sobre las tierras de los pueblos, e impedir que llegaran órdenes a los jesuitas cautivos en los pueblos. En términos generales, el conflicto se presenta como un contexto de redefinición de alianzas políticas y de actualización de los liderazgos nativos. Los jesuitas son acusados por un sector de la elite indígena de traidores y rápidamente se manifiestan tensiones entre el sector de los caciques y el de los funcionarios indígenas del cabildo, afín a los ignacianos.

Durante el conflicto, muchas de las colaboraciones y alianzas estaban basadas en relaciones de parentesco que mantenían entre 
sí los indígenas rebeldes de diferentes reducciones. La historia de desprendimientos poblacionales y la creación de colonias durante todo el siglo anterior, no había cortado aquellas relaciones de afinidad entre pueblos que ahora se veían reactivadas sobre la base de una historia de construcción territorial común. Estas alianzas involucraron rápidamente a reducciones no directamente afectadas por el tratado de límites, como Yapeyú y Concepción. En su crónica de los acontecimientos, el jesuita Nusdorffer relata el encuentro que tuvo el cacique rebelde Paracatú con unos indígenas que venían en una balsa. Al descubrir el cacique que eran sus parientes y que tenían gran habilidad en la navegación, los invitó a quedarse en su compañía y aumentar la flotilla de canoas que había formado. Como contraparte, los aliados le expresaron su deseo de comer "carne gorda” y mandioca del pueblo de Yapeyú. Aparentemente, Paracatú solía entregar lienzo y tabaco a sus soldados, "dejando al Cura de Yapeyú el cuidado de pagarlo después todo al pueblo de San Javier con ganado, y así les parecía todo compuesto con mucho acierto á su modo. Este fue el modo - concluye Nusdorffer - como que los javieristas asistieron à la guerra de sus Hermanos aun sin querer" (NUSDORFFER, [c. 1755] 1969, p. 266).

La escritura, que varios miembros de la elite indígena habían aprendido con los jesuitas, constituyó un vehículo básico de comunicación orientado a la reafirmación de nuevos lazos políticos. Por medio de ella, el ya mencionado cacique Paracatú ordenaba a su hermano menor que guardara bien los papeles que habían quitado a los españoles sin entregárselos a nadie. Por su parte, otro indio llamado Anadeto Candiré escribe en una carta: "Dios nuestro señor quiere que así nos tengan en la tierra a nosotros sus criaturas, y por eso decimos todos que se cumpla todo cuanto pensamos hacer y por sólo deciros esto os escribo mis Caciques. Dios os guarde a todos [...]". Otra carta informa que el corregidor Don Pedro [Taranaa] hizo en su puerta una plática a otros caciques sobre la salida que debían hacer del pueblo y que "Don Crisanto [Tayuaré] llamó a todos los Caciques que querían ir al viaje y también a los Indios de la parcialidad de cada uno" (SUBLEVADOS, [9-10-1754]).

En otra carta, los caciques y otras autoridades de los pueblos escribían a Paracatú que habían seguido todas sus instrucciones: 
"Nosotros no tenemos motivo alguno para apartarnos de vosotros porque así hemos de vivir en adelante en nombre de Dios y de su Santísima Madre María virgen y de nuestro Santo Ignacio Santos Reyes y santos mártires en cuyo nombre os decimos la verdad y es que seis indios de nuestros hijos no parecen aunque vinieron con nosotros desde el Arroyo de las Pabas pero no nos han alcanzado hasta ahora por cuya razón tenemos gran cuidado de ellos y queremos ver en lo que han parado[.] Por eso Parientes míos os rogamos nos perdones por el nombre de Dios que nosotros no haremos otra cosa que lo que desde el principio tratamos; os esperamos en la estancia de las Lecheras para que todos juntos llevemos a nuestra Santísima Madre al Pueblo. No hay más que deciros sino que Dios nuestro Señor os guarde muchas veces y que quiera que nos cuidemos todos los Parientes" (Ibidem). Por su parte, otro cacique importante llamado Nicolás Ñeenguirú, de la reducción de Concepción, escribía en una carta:

[...] aunque tengo cien caballos como camino con sesenta y cuatro Indios te los escaseo; allá os envío mis hijos los de la Concepción y de los Apóstoles doce Indios envío a traer a ese Pueblo que fue para allá y le envío sus Lomillos y que vengan con él todos los Indios que le acompañan y o también siento que ande de esa suerte no se lo que habrá sido del Padre Dios lo sabe (SUBLEVADOS [9-10-1754])

Como lo sugiere Neumann, cabe distinguir en la correspondencia circulante aquella de tono religioso, escrita a partir de formulas marcadas por la retórica cristiana de la época, y las cartas de los líderes más "racionales”, caracterizadas por un lenguaje más concreto e inmediato, donde las fórmulas son más raras. Esto parece revelar una mudanza en la construcción de los argumentos y la emergencia de un nuevo lenguaje, tema que aún debe ser investigado.

Como quiera que sea, el lazo parental, la reciprocidad y la alianza política operaban como un mismo eje articulador de los sublevados. Esto nos lleva necesariamente a examinar una concepción del parentesco guaraní, según la cual los lazos de afinidad y de consanguinidad se encontraban distribuidos por varias reducciones y se reactivaban en las circunstancias del conflicto. 
El parentesco y los intercambios recíprocos podían diluir incluso los tradicionales enfrentamientos con la población no reducida para crear una comunidad de intereses que iba más allá de las fronteras impuestas por la legislación, e incluso de los valores religiosos en que los guaraníes habían sido adoctrinados. En este sentido puede decirse que el conflicto generaba una suerte de espacio de ambigüedad o confusión, donde se redefinían fronteras simbólicas y políticas entre el espacio cristiano y el espacio "infiel". ${ }^{15}$

Ahora bien, la organización de estas "confederaciones" no era estable. Más bien estaba signada por permanentes conflictos basados en antiguas rivalidades entre individuos dentro de una misma reducción o entre pobladores de distintas reducciones. Por otra parte, las lealtades hacia los líderes más importantes eran frágiles. Los "macroliderazgos" por encima del nivel de la reducción tuvieron existencia bastante efímera y tendía a predominar la pertenencia a un pueblo particular y sus parientes, antes que al colectivo "guaraní". El renombre de un cacique circulaba con rapidez de un pueblo a otro, y con la misma velocidad, ese mismo personaje podía perder prestigio y seguidores.

La inestabilidad de las alianzas también se originaba en un conflicto latente entre los caciques, los cabildantes y un sector de la población rezagado que tenía ambiciones de reconocimiento político. Los primeros comenzaron a rechazar a los segundos por considerarlos afines a los sacerdotes, obligándolos a dejar sus insignias, en tanto que los terceros buscaban la mejor oportunidad para intervenir. Nusdorffer relata un caso muy ilustrativo en este sentido. En Yapeyú, el corregidor fue sacado de su cargo por no querer ir a la guerra y el mando quedó repartido entre dos personajes, el ya mencionado cacique Rafael Paracatú y el indio Santiago Caendí.

Desde 1721, Yapeyú se encontraba dividido mitad y mitad por cacicazgos originarios del mismo pueblo y javieristas que habían migrado allí en tiempos anteriores. Caendí y Paracatú representaban respectivamente al sector yapeyuano y javierista. Ahora bien, un padrón del pueblo fechado en 1735, ofrece dos datos significativos: el primero es que Caendí no era cabeza de cacicazgo sino hermano del cacique, el segundo es que su cacicazgo era poco numeroso en comparación con otros originarios del pueblo, apenas 28 personas. 
Este episodio parece indicar que el conflicto se presentó como una oportunidad de ascenso para algunos individuos del pueblo, cuya legitimidad no estaba suficientemente sostenida por su representatividad numérica o su tradición cacical. En momentos críticos como éste, quienes aparentemente tenían mayor legitimidad eran aquellos indios capaces de ejercer influencia inmediata en la población, movilizándola para la guerra aun sin ser caciques (NUSDORFFER, [1755] 1969, p. 251). Aunque ninguno de los dos pueblos en cuestión se encontraba afectado directamente por el tratado, el levantamiento despertaba dentro de ellos tensiones que eran propias de la organización política misional como tal. A ellas probablemente haya que atribuir también la rápida derrota de Paracatú y Caendí. ${ }^{16}$

Los parientes agrupados en diferentes cacicazgos, regían la división interna de la reducción y, en última instancia, también marcaban las disputas por el control de espacios. Puesto que la participación coordinada dependía de la lealtad basada en la inmediatez del parentesco, la emergencia de líderes reconocidos más allá de los límites de sus propios pueblos solo podía tener una existencia temporaria y efímera. Por lo tanto, las alianzas en torno de un gran líder respondían menos a una tradición de unificación que a las particulares circunstancias de la guerra, que impedían a los cacicazgos afrontar la coordinación de las acciones por sí solos.

El conflicto descripto pone en evidencia, por un lado, la capacidad de negociación de los líderes misioneros, quienes dentro del marco establecido, por un lado reclamaban ante el rey y el gobernador por sus derechos adquiridos, y por otro rivalizaban entre sí y con los jesuitas, actualizando el orden interno de las reducciones. La reciprocidad y el parentesco eran los dos mecanismos básicos en la construcción de nuevas alianzas, más allá incluso de los límites territoriales que imponía cada pueblo (con los pueblos no afectados por el tratado), o las fronteras simbólicas que marcaban la pertenencia cristiana (con los "indios infieles" exitosamente convocados para la acción bélica). 


\section{Situación social 2: la expulsión de los jesuitas}

En el año 1768 fue decretada la expulsión de los jesuitas de todas las reducciones del Paraguay. El gobernador Francisco de Paula Bucareli y Ursua fue el encargado de llevar adelante las operaciones durante dos meses intensos en los que retiró de las reducciones a todos los jesuitas e impuso un nuevo gobierno. Con anterioridad, el gobernador se había encargado de ganarse la confianza de los líderes indígenas para que lo ayudaran en el plan. Varios meses antes había solicitado al padre superior de las misiones que enviara a la ciudad de Buenos Aires un cacique y un corregidor de cada uno de los treinta pueblos guaraníes para hacerles conocer la buena voluntad del rey, y que disiparan todo resquemor con respecto a los españoles. En septiembre de ese año llegaron a la ciudad de Buenos Aires 57 líderes guaraníes (27 caciques y 30 corregidores) provenientes de todos los pueblos. Allí fueron recibidos con pompa y agasajados por el gobernador.

Poco tiempo después, los líderes indígenas acompañaron al gobernador Bucareli y su comitiva en su viaje a las reducciones con el propósito de ejecutar el decreto de expulsión de los jesuitas e instaurar un nuevo gobierno. Una cuestión que atrae particularmente la atención al seguir el itinerario de la expulsión es la eficacia y el orden con que fue llevada a cabo. Durante su itinerario, Bucareli se preocupó por consolidar un vínculo perdurable con los líderes que habían colaborado con la expulsión. En una carta dirigida al conde de Aranda relata que a medida que llegaban a su encuentro los guaraníes "[...] los hacía regalar y agregaba a los corregidores y caciques, quienes les comunicaban el buen trato, mostrándoles sus vestidos y los que llevaban para sus mujeres" (BRABO, 1872, p. 189). De esta manera se ganaba hábilmente la confianza de los líderes y de la población que los seguía, desechando sus temores.

En su itinerario, Bucareli tuvo un encuentro con el conocido cacique Nicolás Ñeenguirú, quien se le acercó con el objeto de mantener una entrevista. Bucareli ya sabía del cacique por las "gacetas extranjeras" que lo asociaban con el mítico Nicolás Primero del Paraguay. En ocasión del encuentro, Bucareli lo hizo vestir al igual que a los demás caciques y lo invitó a sumarse a su comitiva. Luego 
observó la actitud de reverencia que observaban frente a él los demás caciques: "[T]raía criado que le tomaba el caballo, distinción que ninguno usaba, y lo que más noté que, cuando se desmontaba, hasta los mismos caciques le tenían el estribo y le trataban con atenta veneración" (Ídem, p. 177). Ñeenguirú aceptó formar parte de la comitiva y luego se mudó a vivir a Buenos Aires con su familia, donde fue mantenido a expensas de la corona.

Aun varios meses después de llevada a cabo la operación de expulsión en los pueblos, algunos líderes mantenían correspondencia con el gobernador en agradecimiento a su "generosidad". Al regresar a Buenos Aires, Bucareli recibió una carta del corregidor Don Miguel Yeguacá desde el pueblo de la Cruz que le daba

[...] infinitas gracias con todo mi cabildo, caciques y toda mi familia, agregándose también, la elección tan bella, de habernos tocado unos sujetos, así los religiosos que tenemos, como el señor administrador Don Joseph Benites, quien nos mira como a hijos de sus entrañas, con tanto amor, caridad, y lástima. En este no tengo más que decir que lo dicho, y que Vuestra Excelencia hubiese tenido feliz viaje nos alegraremos infinito, y damos a VE repetidas gracias. Por tantos beneficios, Dios guarde a VE más años (YEGUACÁ [22-9-1768]).

Un año más tarde, Don Chrisanto Tayuaré de Yapeyú le agradecía por haberlo nombrado teniente corregidor de ese pueblo (TAYUARÉ [28-11-1769]). ${ }^{17}$

En todo el proceso, la relación entre el gobernador y los líderes introducía la novedad del intercambio directo, sin la mediación y control de los jesuitas. Si bien los guaraníes reglamentariamente viajaban a Buenos Aires, para ser reconocidos por el gobernador o realizar servicios de diferente tipo, el intercambio descripto era una novedad pues no estaba sometido a la vigilancia de los sacerdotes. Como se sabe, los jesuitas eran defensores activos de la separación residencial de la población indígena, restringiendo contactos prolongados entre los guaraníes y los españoles. La idea del "encierro" o "exclusivismo", como la ha llamado Susnik, había consolidado determinados valores culturales misioneros diferenciados (SUSNIK; 
CHASE-SARDI, 1992, p. 154). De modo que la reciprocidad con el gobernador y la serie de episodios descriptos constituía una verdadera reconfiguración de las relaciones de los indígenas con el mundo español. Estos episodios disolvían al menos temporariamente la división de las dos repúblicas creando un espacio de "liminaridad" en donde los intercambios eran posibles.

Al poco tiempo, esta política de acercamiento se profundizaría con las reformas que implementó Bucareli, a través de las cuales extendía la adopción de hábitos y estilos de vida españoles a toda la población guaraní. En un visionario espíritu asimilacionista, el gobernador afirmaba que los "naturales" eran "dóciles y humildes, y su comprensión como la de otras naciones de Europa” (BRABO, 1872, p. 197), lo que hacía posible extirpar la "odiosa separación" que los distinguía de los españoles. Bucareli instrumentaba en su favor el prestigio de los símbolos españoles seduciendo a los indios por medio de concesiones. A su vez, ciertos líderes indígenas veían satisfechas en la adopción de dichos símbolos sus ambiciones de ascenso político y social. Este circuito de intercambios simbólicos no solo refedefinía las relaciones con el mundo español sino que reordenaba el mapa político-social interno de las reducciones.

Durante más de una centuria, el vínculo entre el rey y los guaraníes había estado mediado casi siempre por los jesuitas. Y puede decirse que la legitimidad de estos últimos ante la población indígena dependía del éxito en sus gestiones con la corona para obtener beneficios para las reducciones. La llamada "guerra guaranítica" había socavado la relación de varios pueblos guaraníes con la corona, pero sobre todo con los jesuitas, sospechados de traición. Los miembros de la orden habían ido perdiendo gradualmente su influencia en la definición de las políticas indigenistas.

En este sentido, el contexto de la expulsión puede ser considerado como un momento de redefinición de las relaciones sociales y políticas. Durante el período que se desenvolvieron las operaciones, se instituía un vínculo directo entre los líderes guaraníes y el rey, que remitía al pacto originario que habían sellado en la fundación de sus pueblos y consolidado en la historia de colaboraciones y servicios brindados durante más de 150 años. Simultáneamente se restituía una confianza perdida y se eliminaba a los jesuitas, entonces acusados 
por sus enemigos de pretender formar un "imperio" en los confines americanos.

El proceso de la expulsión ofrecía a los guaraníes una oportunidad para reconstituir su vínculo con el mundo español, pero sobre todo la posibilidad de redefinir sus relaciones políticas dentro de la reducción. El desprestigio jesuita y la necesidad de ascenso de algunos líderes, del sector de los caciques, coincidían con las pretensiones de los representantes del rey de acercarse más a sus súbditos.

\section{Situación social 3: un conflicto postjesuítico}

El 19 de noviembre de 1778, los habitantes de Yapeyú se vieron consternados por la decisión del teniente de gobernador español, Juan de San Martín, de confiscar la vara de alcalde al cacique Melchor Aberá y ponerlo preso con grillos y cepo en la cárcel de pueblo, acusándolo de haber conducido irresponsablemente una vaquería del pueblo. La pena impuesta a Aberá produjo indignación entre los indígenas por considerarla excesiva para un "cacique principal", lo que se sumaba a la animadversión que el funcionario español ya motivaba entre los indios por episodios anteriores de abuso de autoridad.

Dos líderes del pueblo, el alcalde provincial Félix Arey y el cacique Ignacio Azurica, decidieron poner freno a San Martín. Reunidos el 20 de noviembre por la mañana en la casa capitular con los demás caciques redactaron un memorial solicitando la libertad de Aberá. A las siete y treinta de la tarde hicieron sonar la campana del cabildo y acudieron a la plaza cincuenta indígenas. Allí irrumpieron en el edificio del colegio que era la residencia del teniente de gobernador, quien se encontraba junto al administrador y un soldado.

Mientras empuñaba su vara de cabildante, Arey reclamó al teniente de gobernador se le dijesen los motivos de la detención de Aberá. Mientras tanto, Pastor Tayuaré, quien había escrito el memorial con el incentivo de Miguel Taperoví y la colaboración de los demás, comenzó a leerlo en voz alta. Con enojo, San Martín y el administrador ordenaron a ambos líderes retirarse del lugar, pero éstos se resistieron. Entonces, exasperado San Martín ciñó su espada 
y exigió a Arey que dejase la vara en la puerta para hablar con él. Arey le respondió "con voz airada meneando la vara" y golpeando con ella en el suelo, "que si él era mburubichá, también él lo era, y que aquella vara se la había dado Dios y el Rey” (LABOUGLE, 1941, p. 57). A continuación, San Martín ordenó a sus colaboradores que cargaran armas exhortando nuevamente a los líderes a retirarse del lugar y les prometió que serían recibidos al día siguiente, luego de lo cual se retiraron dejando en sus manos el memorial que habían redactado.

A la mañana siguiente, San Martín se dirigió al cabildo acompañado de soldados armados. Allí encontró a todos los caciques y cabildantes reunidos. Al entrar en la sala descubrió un retrato del rey y se puso debajo de él. Luego preguntó a los cabildantes qué era lo que querían. Estos respondieron que debía poner de inmediato en libertad al cacique Aberá y cederles las llaves del cepo. San Martín se negó e intimó a Arey, que era alcalde provincial, a que se entregarse preso "en nombre del rey". Increpó a Arey diciéndole que "no era cacique", pero inmediatamente los demás caciques lo defendieron respondiéndole que sí lo era "y que el que estaba preso lo era Principal". Las autoridades del cabildo alegaron que según les había dicho Don Francisco Bucareli, San Martín estaba allí "para quererlos", a lo que el teniente respondió que todo era falso y que el gobernador había dicho aquello solo con el fin de sacar a los jesuitas. Los líderes insistieron en que ya antes les había dicho lo mismo Don Pedro de Cevallos siendo todo "palabra del Rey" (Ídem, p. 173-174).

La tensión aumentaba y Don Félix Arey salió de la sala y comenzó a arengar a los soldados diciéndoles: "Mirad hijos que por habernos humillado, me quiere poner preso el señor teniente, mirad por nosotros y tenednos lástima que nosotros también por mirar por los caciques estamos así" (Ídem, p. 58). Los soldados - entre los cuales había dos sargentos llamados Agustin Biyui y Apolinario Baracayacua - arrojaron sus armas y se sublevaron con Arey. Acto seguido, se dirigieron todos a la cárcel para liberar a Aberá y con la ayuda del herrero, Ygnacio Yacibera, abrieron el cepo al preso. En una declaración contenida en la sumaria, el teniente de corregidor Don Miguel Xavier Taperoví afirma que se dirigió a la cárcel tratando de reconvenir a los sublevados y los halló junto al preso. Fue entonces que uno de los caciques llamado Don Martín Parapuy le dijo: 
[...] que si el era superior era solo por el Bastón que tenia pero que si ellos se lo quitaban no era naides y que ellos siempre quedaban como cuerpo de Caciques y que Don Félix Arey le dijo que yo y los caciques lo hemos sacado ya que vos no miráis por ellos y les dijo en público a los Indios y chinas a mi me debéis reconocer por superior pues tengo muchas facultades y habiendo traído a la presencia del Señor teniente de gobernador oyó el que declara le dijo el mencionado teniente de gobernador que estaba bien lo que habían echo pero que no oyó que Don Melchor Aberá hablare nada ni los caciques. (LABOUGLE, 1941, p. 165, [c.p.])

Otro testigo, el regidor Don Ignacio Cusuburá, declara que encontró a Arey con otros caciques en la cárcel y que Don Félix Arey les dijo: "Vosotros no miráis por vuestros prójimos, de balde estáis en cabildo, nosotros los caciques somos quien lo hemos puesto en libertad" (Ídem, p. 171).

Los sublevados sabían que el Teniente de Gobernador actuaba en contra de la legislación y buscaron inmediatamente la aprobación y apoyo del corregidor y los cabildantes. Así pues, Juan Pastor Tayuaré redactó una carta en nombre de los caciques al corregidor Don Abraham Guirabo, en la que relataba lo ocurrido entre San Martín y Melchor Aberá, y calificaba de injusta la determinación del funcionario. También expresaba una queja de los caciques contra los trabajos que se imponían a sus hijos y las injusticias que padecían sin tener quien los defendiera.

A los pocos días Don Azurica había corrido la voz entre los guaraníes de que San Martín había pactado con los minuanes, sus enemigos, para que los asesinaran. Los sublevados dirigieron también una carta al pueblo de La Cruz en la que informaban de los sucesos a los caciques y cabildantes de ese pueblo, llamándolos de "parientes", "amigos" y "paisanos". Les comunicaban que se les había acabado la paciencia después de la grave injuria o "tiranía" que habían sufrido, lo que los había llevado a sublevarse.

Por su parte, San Martín solicitó auxilio al gobernador de las Misiones, Don Francisco Piera, quien llegó el 14 de diciembre a Yapeyú junto con 30 hombres de tropa, poniendo presos de inmediato 
a los principales implicados en la sublevación y designando un juez comisionado. Fueron arrestados los caciques Don Juan Pastor Tayuare, Don Juan Guarira, Don Bartolome Cararu, Don Francisco Xavier Airuca, Don Martin Parapuy y los mboyas Fausto Penda, Cordnelio Berréate. En el ínterin habían tenido tiempo de escapar Félix Arey, Ignacio Azurica y Melchor Aberá, quienes habían ordenado en los diversos puestos de las afueras no dar auxilio a los emisarios españoles del pueblo ni obedecer las órdenes de San Martín. Tampoco pudieron atrapar a Don Ilario Tabacoy, Don Justo Andi, Don Francisco Cabure, Don Ignacio Xavier Tabaca, considerados cómplices (Ídem, p. 196).

Durante las dos semanas siguientes se investigaron los hechos. En su dictamen final, el fiscal consideraba el hecho una conspiración punible, sin embargo, agregaba que era conveniente que se suspendiera a Don Juan de San Martín por su inmoderación en la prisión de Aberá sin guardarle los fueros y excepciones que le correspondían. Escribía el fiscal:

[...] a fin de que conozcan dichos Naturales, que la Justicia se distribuye, según la proporción, que es debida no permitiendo sus vejaciones: ni menos en ellos la trasgresión de los preceptos de los superiores, que en nombre del Soberano (que Dios guarde) gobiernan aquellos Pueblos, que así lo siente en Justicia. (LABOUGLE, 1941, p. 61)

Por su parte, el protector de naturales, Zamudio, señaló que el teniente gobernador había sido imprudente al proceder con tanto rigor y que en realidad había cometido un atentado "[...] pues el cacique estaba constituido en empleo honorífico, y no lo debió poner en la cárcel, ni en prisiones, y mas por un delito que no merecía tal pena, como es notorio" (LABOUGLE, 1941, p. 62). El Virrey finalmente decidió sobreseer a los caciques y demás presos y ordenar a San Martín que los pusiera en libertad. Exigió además a San Martín guardar los fueros y privilegios correspondientes a los caciques y demás personas que se hallaban empleados en algún cargo 
[...] tratándolos, y a los demás Indios con la moderación que es debida, y humanidad, que se previene en las Reales Leyes y pragmáticas de S. M. Sin dar causa a que dichos Naturales se alteren ni alboroten, pues de lo contrario será responsable de los daños, y perjuicios, que se originen y se le impondrán las demás penas correspondientes (LABOUGLE, 1941, p. 63).

Así concluía el conflicto.

$\mathrm{Al}$ menos dos aspectos en particular resultan reveladores de los episodios descriptos: primero, la clara conciencia de la elite indígena de sus derechos frente a las pretensiones de los funcionarios coloniales. Segundo, las tensiones internas entre las mismas autoridades guaraníes, especialmente aquellas que oponen los caciques a los cabildantes. Ambos aspectos revelan que no se trataba de un sector homogéneo ni pasivo. Es interesante observar que los líderes, como en tantas otras ocasiones, utilizaban la legislación como instrumento de reclamos ante las autoridades, resaltando las promesas que les hicieron los gobernadores, e indirectamente, el mismo monarca. La identidad política de los cabildantes es reforzada mediante la apelación a los emblemas o atributos de poder como las varas y bastones, que se utilizaban como vehículos de legitimidad. Estas armas simbólicas resultaban más eficaces que los débiles argumentos del teniente gobernador. No obstante, tanto unos como otros recurrían a la figura del monarca para legitimarse. El teniente gobernador, descubriendo y colocándose debajo del retrato y los líderes guaraníes señalando los muchos servicios prestados a la corona.

Una segunda cuestión que debe destacarse del conflicto reseñado es la emergencia de un sentido de pertenencia colectivo de los caciques en oposición al bando de los cabildantes. La condición de "cacique" o mburubichá se colocaba en el centro de la disputa con el teniente gobernador. Cabe subrayar sobre todo las frecuentes apelaciones al "nosotros los caciques" como indicio de pugnas no resueltas entre las autoridades tradicionales y las impuestas en los tiempos jesuíticos, cuyos límites, como ya se ha dicho, no eran siempre del todo claros.

El caso revela la existencia de redes y alianzas creadas por las autoridades indígenas, en las que participaban también los indios del 
común, interesados en obtener protección o ascender socialmente. El cabildo se presentaba entonces no solo como una institución fundamental para ejercer el poder, sino también para disputar legitimidades, especialmente en el contexto posterior a la expulsión de los jesuitas.

La dinámica política de los pueblos guaraníes después de 1768 estuvo marcada por dos aspectos en particular. El primero fue el mantenimiento y reforzamiento de los cabildos indígenas, dando mayor participación a los caciques. El segundo fue la separación estricta de funciones temporales y espirituales a cargo, respectivamente, de administradores y sacerdotes. Los nuevos religiosos franciscanos, mercedarios y dominicos tenían prohibido intervenir en los asuntos político-económicos de los pueblos debiendo restringirse a la administración de los sacramentos. Cada pueblo tendría un administrador particular que, junto con el corregidor y el mayordomo indígenas, se ocuparía de la producción comunitaria controlando, cada uno, las tres llaves disponibles de los almacenes.

Después de la expulsión, el cabildo indígena siguió siendo la institución política central de los pueblos. Las disposiciones de Bucareli habían establecido una composición estándar para el mismo que incluía los cargos básicos de la época jesuítica y que se mantuvo por lo menos hasta finales del siglo XVIII. La ausencia de los jesuitas y las concesiones otorgadas por Bucareli contribuyeran al aumento del peso de esta institución y de las oportunidades de acceso a empleos por parte de un sector de la población guaraní que hasta entonces se encontraba relegado.

Como ya se ha visto, los jesuitas habían mellado progresivamente el poder de los caciques, preparando una nueva "casta burocrática" más afín a ellos que ocupara las funciones de gobierno. Después de la expulsión, el gobernador Bucareli invirtió esta lógica favoreciendo a los caciques para los empleos de corregidor y cabildante. El funcionario Zavala se queja de que "[... [] [] política de los jesuitas tenía abatidos a los caciques a pocos de ellos los instruían a leer y escribir solo echaban mano de los muchachos que criaban ya en su servicio y en sacristanes y músicos, por este motivo raro cacique hay que sepa leer y escribir" (ZAVALA, [31-8-1770b]). Por contraste, las órdenes explícitas del gobernador eran colocar en el cargo de corregidor a los caciques. Además, trató de dejar clara la 
importancia de la diferenciación de rangos y jerarquías entre los diferentes individuos, las que debían hacerse visibles mediante la asignación de atributos y espacios de poder. De acuerdo a las disposiciones, los caciques y cabildantes debían ser acreedores de honores y todos debían llevar vara como insignia de su oficio.

Este tercer episodio ilustra el un nuevo proceso de actualización y reacomodación del poder político y social dentro de los pueblos de reducción en el que los líderes indígenas tienen una participación decisiva. Importa destacar que el marco de estas reconfiguraciones sigue siendo la legislación indigenista impuesta por la corona española, aceptada y negociada por la población indígena en un momento, fines del siglo XVIII, en que comienzan a sentirse los primeros efectos de las reformas ilustradas.

\section{Reflexiones finales}

La reducción constituye una configuración socio-política específica resultante de un proceso de sedimentación histórica singular en el que la formación y la trayectoria de las elites indígenas juega un rol fundamental. El análisis de la construcción del liderazgo indígena implica investigar a fondo las características de ese contexto histórico específico. En la definición del poder nativo de la reducción confluyen la legitimidad basada en el carisma, la generosidad y la destreza guerrera, el respeto derivado de poseer un cargo del cabildo, la estructura militar y eclesiástica, el ejercicio de algún oficio o el conocimiento de técnicas como la escritura. En la investigación sobre estas autoridades no importa tanto la caracterización de "tipos políticos" como el análisis de los mecanismos y lógicas que generan y actualizan la autoridad al nivel de las relaciones cotidianas y de los procesos locales.

En términos generales, las tres situaciones o contextos analizados constituyen eslabones de un mismo proceso de transformación del poder nativo en las reducciones, tanto hacia adentro de la elite indígena, como hacia afuera, en el terreno de las relaciones de los indígenas con el mundo hispano-colonial. En su formación, el régimen reduccional genera divisiones persistentes en la elite indígena, 
marginando progresivamente a los caciques de la estructura político institucional de los cabildos y las milicias, lo que genera tensiones constantes que emergen en las situaciones de conflicto analizadas, en las que sectores de la elite indígena perciben oportunidades de ascenso social. Simultáneamente, las situaciones en cuestión redefinen el vínculo de esas elites con el mundo español: en términos políticos, la "guerra guaranítica" define una antesala de la expulsión, en la medida que instala una desconfianza de la elite indígena con respecto a los jesuitas, incrementando y haciendo más directa la comunicación con las autoridades seculares. Esto se manifiesta en el gradual aumento de la documentación en lengua española y la difusión entre los indígenas de nuevos géneros textuales (como los "memoriales", en muchos casos bilingües), en los que los indígenas apelan directamente a las autoridades coloniales. En este sentido, el manejo de los códigos hispanos (lingüísticos pero también jurídicos) comienza a ser valorado y utilizado por los líderes especialmente después de la expulsión de los jesuitas, como instrumentos para el acercamiento directo a las autoridades coloniales.

Las situaciones sociales críticas, en la medida que introducen un quiebre en el fluir cotidiano, aumentan el grado de tensión (siempre existente) de las relaciones preestablecidas, impulsando reacomodaciones y actualizaciones. Su reconstrucción permite profundizar en la operatoria de las estrategias indígenas y cuestionar modalidades de abordaje antropológico excesivamente estáticas, delineando lo que podríamos considerar como un modelo generativo y procesual de análisis del liderazgo indígena.

\section{BETWEEN POLITICAL TYPOLOGIES AND SOCIAL PROCESSES: ELEMENTS FOR THE SITUATION ANALYSIS OF INDIGENOUS LEADERSHIP IN A COLONIAL BORDER.}

Abstract: This article proposes a model of analysis of indigenous leadership based on the reconstruction of social situations. Taking as a case the context of Jesuit *reducciones* of Guarani, the article analyses the transformations of native power over the long-term. The first part describes the formation of a new political organization emphasizing the relations between mission ethnogenesis and the institution of political figures of indigenous leaders - the "caciques" and "cabildantes"- that participated of mission government. The second part analyzes the participation of indigenous leaders in three critical situations of the 
history of reducciones: the Guarani war, the Jesuits' expulsion and the post-jesuit period. In a broader framework of rearrangements of the political and institutional map of the reducciones and the Colonial State, each of these situations constitutes a complex context in which power relations are reconfigured and native agency shaped.

Keywords: Indigenous leadership. Cabildos. Guaraní. Jesuit reducciones.

\section{Notas}

${ }^{1}$ Esta investigación fue realizada con el apoyo del Consejo Nacional de Investigaciones Científicas y Técnicas (CONICET, Argentina) y de la Sociedad Japonesa para la Promoción de la Ciencia (JSPS). El artículo replantea críticamente buena parte de las reflexiones volcadas en Wilde (2005). Agradezco a Fabio Mura y Eduardo Neumann las agudas críticas y sugerencias durante la preparación del texto. ${ }^{2}$ Para un recorrido exhaustivo de los modelos de análisis del liderazgo ver Feinberg y Watson-Gegeo (1996); Uribe y Drennan (1987); Johnson y Earle (2000); Haas 2001; Villamarin, Juan y Judith (1999). Uno de los pocos trabajos específicos sobre el liderazgo en la zona amazónica es el de Waud Kracke (1978). Para un debate sobre el liderazgo en esa región ver la compilación del mismo autor (Kracke 1993). Algunas discusiones sobre el tema fueron incluidas en un número de $L$ 'Homme dedicada a Amazonia (DESCOLA; TAYLOR 1993). Debe destacarse que en contraste con la situación sudamericana, regiones como Oceanía, que curiosamente muestran muchas similitudes con las tierras bajas americanas han tenido intensos debates sobre el tema en los últimos cuarenta años, en especial a partir de los aportes de Marshall Sahlins. En un trabajo clásico, dicho autor compara los sistemas políticos de Polinesia y Melanesia como dos “tipos ideales" opuestos. En el primero, el líder obtiene su legitimidad de una estructura social preexistente, de un "cargo" de autoridad institucionalizado. En el segundo, el líder construye su prestigio personal y carisma a partir del esfuerzo personal y la legitimidad que luego de sus actos le otorga del grupo al que se dirige. (SAHLINS 1985). Para discusiones posteriores sobre la figura del "big-man" ver Feinberg e Watson-Gegeo (1996); Godelier y Strathern (1991).

${ }^{3}$ Podemos constatar que este programa de antropología política comparativa de orden global hunde sus raíces en una inquietud ya instalada en los primeros escritos de los cronistas de la conquista. Sobre el tema ver los artículos incluidos en una reciente compilación de Giudicelli (2010).

${ }^{4}$ A propósito de la orientación metodológica adoptada en este artículo, resulta pertinente retomar la discusión presente en la antropología contemporánea sobre 
diferentes modalidades de producción teórica a partir de los casos etnográficos. Así, por ejemplo, Fredrik Barth opone modelos estructurales a modelos procesuales o generativos. Según el autor, más que buscar patrones estructurales, “[...] [d] everíamos empregar metáforas de processos, atividades direcionadas para um foco, mudancas marginais, transformacoes cumulativas, e sobretudo pensar de maneira mais imaginativa em termos de modelos determinados de procesos formadores e gerativos" (BARTH 2000, p. 165). Por su parte, Carlo Severi opone aproximaciones "intensivas" y "extensivas" de producción teórica. Escribe: "[...] theory can be either powerful (accounting for a limited number of features valid for a great number of cases) or expressive (accounting for a great number of features belonging to a limited number of cases). In other words, theories can be extensionally or intensionally oriented. Any case-centred inquiry (for instance, a clinical study) is in some measure intensional, while any comparative or statistical analysis tends to be extensional" (SEVERI, 2004, p. 816). El análisis histórico del liderazgo indígena que aquí propongo está cerca de una aproximación tanto intensiva, como procesual y generativa.

${ }^{5}$ La idea de una transformación del poder nativo debida a factores endógenos es propuesta por los esposos Clastres (Clastres, H., 1989; Clastres, P., 1974). Nos hemos detenido en una crítica de dicho abordaje en Wilde (2005 y 2009; ver también Descola, 1988 y Fausto, 1992). De todas maneras, tampoco somos partidarios de la visión según la cual la estructura política indígena de la misión es el resultado exclusivo de la imposición externa del régimen colonial. En este sentido recuperamos una serie de trabajos de la etnohistoria colonial centrados en la formación de organizaciones políticas a partir del contacto en zonas de frontera. Ver por ejemplo Ferguson y Whitehead (1992), a propósito de las "tribal zones", y los diversos trabajos sobre etnogénesis en las Américas, como Sider (1994) y Hill (1996). La discusión sobre las nociones de middle ground, mestizaje y territorialización, resultan pertinentes a propósito de estos contextos (Pacheco de Oliveira, 1998; White, 1991; Gruzinski, 1999).

${ }^{6}$ Recupero de Barth la noción de "tradición" como flujo continuo de experiencias cotidianas que permiten el acceso a materiales y conocimientos. Esto implica cuestionar una visión reificada de la cultura como un campo predefinido del que los individuos extraen contenidos para la acción y establecer una definición según la cual, el flujo continuo de relaciones sociales que modela constantemente los significados culturales de los que los individuos hacen uso en su experiencia cotidiana. En este sentido, la unidad de análisis no serían las estructuras de pensamiento sino las valoraciones que los individuos concretos ponen en juego en sus interacciones sociales (BARTH, 1987).

${ }^{7}$ Por motivos de espacio, este artículo recupera de los acontecimientos en cuestión solamente aquellos aspectos relacionados con la construcción de los liderazgos 


\section{Entre las tipologías políticas y los procesos sociales...}

políticos. He tenido oportunidad de tratar sobre cada uno de estos acontecimientos de manera más exhaustiva en otros textos publicados anteriormente. Para más detalles remito especialmente a mi libro Religión y poder en las misiones guaraníes (WILDE, 2009b).

${ }^{8}$ Para una síntesis del proceso de formación de las misiones ver Maeder (1989). Sobre las relaciones entre etnogénesis y formación misional ver Wilde (2009a; 2009b; 2011). Las reducciones no se establecieron como organización estable sino hasta el siglo XVIII. Una periodización implica necesariamente tener en cuenta las constantes relocalizaciones de población ocurridas a lo largo de los siglos XVII y XVIII - motivadas por los ataques bandeirantes, las epidemias, el hambre, los factores geopolíticos y administrativos -, las cuales contribuyeron a la mezcla de individuos provenientes de diferentes regiones y a la creación de una nueva sociedad en las fronteras ibéricas.

${ }^{9}$ El jesuita Antonio de Ruiz de Montoya escribe en 1640: “Tenían sus caciques, en quien todos reconocen nobleza, heredada de sus antepasados, fundada en que habían tenido vasallos y gobernado pueblo. Muchos se ennoblecen con la elocuencia en el hablar (tanto estiman su lengua, y con razón, porque es digna de alabanza y de celebrarse entre las de fama) con ella agregan gente y vasallos, con que quedan ennoblecidos ellos y sus descendientes. [...] Conocimos algunos destos que tenían a 15, 20 y 30 mujeres" (RUIZ DE MONTOYA [1639] 1989, p. 76). ${ }^{10}$ Acompañando la organización municipal gradualmente se educa una elite indígena afín a los jesuitas, dedicada al ejercicio de algunas tareas espirituales. Los empleos de iglesia (sacristán, músico y copista, etc.) y las asociaciones conocidas como "congregaciones" - dedicadas al Arcángel San Miguel y a la Virgen Maríafueron esenciales en este sentido. Para el caso de Moxos, Akira Saito estudia el caso de los llamados "domésticos", "criados de casa" o "familiares", sirvientes de los misioneros que vivían en la casa parroquial y se ocupaban de los quehaceres domésticos, ayudando también a los jesuitas en actividades litúrgicas y visitas diarias a los enfermos. Estos sujetos solían ejercer oficios como los de músico, sacristán, enfermero, pintor, carpintero, herrero, tejedor, entre otros (SAITO, 2011). ${ }^{11} \mathrm{El}$ análisis de la dinámica de los cabildos indígenas es un tópico que ha sido poco explorado hasta el momento, sobre todo en las regiones periféricas como el Paraguay. Esta institución política debe ser considerada como parte esencial del proceso de etnogénesis misional, pues la identidad de los pueblos y la reconfiguración del poder nativo estuvo inextricablemente unida a su formación y perdurabilidad. Los estudios existentes señalan que los cabildos fueron consolidándose a lo largo del tiempo, tanto en su estructura interna como en las prácticas a ellos asociadas. Necker afirma que si bien el cabildo no existía en el Paraguay para 1600, ya se utilizaba el término "corregidor" en 1599 como atribución de los caciques principales de los pueblos de indios franciscanos. Según supone el autor, el corregidor era el heredero del jefe de teko'a precolombino (NECKER

Anos 90, Porto Alegre, v. 18, n. 34, p. 19-54, dez. 2011 


\section{Guillermo Wilde}

1990, p. 184). Sobre cabildos guaraníes ver Díaz de Zappia (2003), Morinigo (1990) y Wilde (2003c; 2009b).

${ }^{12}$ Don Pedro Enocoye, cacique de la reducción de San Miguel, y Gaspar Añangue, capitán de la reducción de Apóstoles, fueron nombrados capitanes por Arias de Saavedra, por haber servido en la guerra contra indios rebeldes. En la compañía de Enocoye fue nombrado alférez Simón Ayquabybe. En 1643 el gobernador de Buenos Aires otorgó título de "capitán general y justicia mayor" de las reducciones del Uruguay a Ignacio Abiarú, cargo que aparentemente también ocupó Nicolás Ñeenguirú, cacique de Concepción (SALINAS, 2006; HERNÁNDEZ, 1913). Francisco de Céspedes nombraba "capitán" al cacique Ayao con una insignia para que "acuda a las cosas de la guerra contra los indios infieles que les ofendieren" y mandaba "a los naturales sus vasallos y sujetos le acaten por su capitán y obedezcan sus mandatos en todo lo que se les ordenare y mandare..." (SALINAS 2006, p. 270-271). En 1640 varios caciques fueron nombrados por Don Ventura Mujica, entre ellos "Nicolás Nenguirú" [sic] de Concepción, Francisco Bairobá, Antonio Guaracica, de San Nicolás, Teodoro Iambatay de San Carlos, Francisco Abié de San Miguel, Roque Guiracazú de San Cosme. Junto con el de capitán, otros cargos eran maestre de campo, 1639 otorgado por Pedro de Lugo y Navarro a Antón Arambaré en Itapúa.

${ }^{13}$ Sobre la relación entre territorialidad, organización política y militarización en la frontera ver Ferguson y Whitehead (1992).

${ }^{14}$ La descripción etnográfica de situaciones es una tradición de largo aliento en la antropología. Particularmente inspiradores resultan los estudios pioneros de Max Gluckman y sus discípulos de la Universidad de Manchester. Entre los ensayos más inspiradores para la aproximación que proponemos se encuentran el clásico Analysis of a Social Situation, de Max Gluckman (1940-1942), y los ensayos de Victor Turner incluidos en Dramas, Fields and Metaphors (TURNER, 1974). Para una formulación teórico-metodológica de este tipo de análisis ver Swartz (1968) y los desarrollos posteriores de una antropología de la política. La microhistoria ha desarrollado mucho más tarde algunas de estas estrategias metodológicas, proponiendo la reconstrucción de redes sociales complejas, especialmente en los trabajos de Giovanni Levi (REVEL, 1995).

${ }^{15}$ La mezcla de guaraníes misioneros con "indios infieles" de la campaña era una constante, especialmente durante la segunda mitad del siglo XVIII. También cabe destacar la constante incorporación de estos indios a los pueblos ya constituídos, y el hecho destacable de que solían conformar "barrios" separados dentro de ellos. Sobre el tema pueden consultarse trabajos recientes de Bracco (2004); García (2009); Wilde (2003a; 2003b; 2011).

${ }^{16}$ En el padrón de 1735 correspondiente al pueblo de Yapeyú, podemos comprobar que dentro del total de 55 "casas", el cacicazgo javierista de Paracatú es uno de los más numerosos. También aparecen mencionados los siguientes

Anos 90, Porto Alegre, v. 18, n. 34, p. 19-54, dez. 2011 
nombres: Caburé, [Panayui], Guarira, Aybi, Arey, Cuzu, Mbiruay, Atira, Ayruca, Tabacá, Papayu, Guayuyu, Mangure, Tayuaré, Mbigui, Piribera. Todos los demás cacicazgos eran yapeyuanos. En el de Caendí (32) aparece como cabeza Andrés Caendí, de 19 años. De Santiago Caendí se indica que era un niño huérfano de 12 años (Padrón Misiones [1735]). Las crónicas indican que éste último tuvo un rol importante durante el conflicto. Después de la muerte de su compañero Paracatú, fue nombrado unánimemente corregidor de los yapeyuanos (NUSDORFFER [c. 1755] 1969, p. 274, p. 276).

${ }^{17}$ En ese mismo año, Bucareli también había recibido una carta del funcionario José de Añasco, quien estaba a cargo de 20 de los pueblos guaraníes, la cual señalaba que las autoridades de los pueblos le agradecían los beneficios otorgados y le adjuntaba los originales de varios documentos con sus traducciones. Escribía: "Quedan Excelentísimo Señor estos pobres con indecible gozo. A porfía vienen unos después de otros a hacerme sus largas relaciones, que concluyen dando infinitas gracias a dios, al rey, y a Vuestra Excelencia, de cuya piedad y amor los dejo muy satisfechos y asegurados". Añasco continuaba informando que, conforme a las órdenes del gobernador, había puesto en libertad y posesión de su empleo al corregidor del pueblo Don Juan Paracatú (encarcelado por el funcionario Riva Herrera) y que eso había sido de enorme regocijo para la población guaraní, que le dio las gracias "en una frase, que enternecía a todos como si con Vuestra Excelencia mismo estuvieran hablando" (AÑASCO, [6-5-1769]).

\section{Referencias}

AÑASCO, José de. [6-5-1769] Carta al gobernador, Candelaria, 6 de mayo de 1769. Archivo General de la Nación, Argentina (AGN) IX.18.5.1.

BARTH, Fredrik. Cosmologies in the making: a generative approach to cultural variation in inner New Guinea. Cambridge: Cambridge University Press. 1987.

. O guru, o iniciador e outras variacoes antropológicas. Rio de Janeiro: Contra Capa Livraria, 2000.

BRABO, Francisco Javier. Colección de documentos relativos a la expulsión de los Jesuitas de la República Argentina y del Paraguay en el Reinado de Carlos III. Madrid: Est. Tip. José María Pérez, 1872.

BRACCO, Diego. Charrúas, guenoas y guaranies. Interacción y destrucción: indígenas en el Río de la Plata. Montevideo: Linardi y Risoo, 2004.

CLASTRES, Hélène. La tierra sin mal. Buenos Aires: Ed. del sol, 1989.

CLASTRES, Pierre. La société contre l'État. Paris: Les édition de minuit, 1974.

Anos 90, Porto Alegre, v. 18, n. 34, p. 19-54, dez. 2011 


\section{Guillermo Wilde}

DEL TECHO, Nicolás. Historia de la Provincia del Paraguay de la Compañía de Jesús. Madrid: Librería y casa Editorial A. de Uribe y Compañía. (6 tomos), 1897.

DOBLAS, Gonzalo de. Memoria histórica, Geográfica, política y económica sobre la Provincia de Misiones de indios guaraníes. En; Colección de Angelis. Buenos Aires: Imprenta del Estado, [1785] 1836-1837.

DESCOLA, Philippe. La chefferie Amérindienne dans l'Anthropologie politique. Revue Francaise de Sciences Politiques, v. 38, n. 5, p. 818-827, 1988.

DESCOLA, Philippe; TAYLOR, Anne Christine (Ed.). L'Homme. La remontée de l'Amazone 126-128. Revue francaise d'Anthropologie. École des Hautes Études en Sciences Sociales. Paris, 1993.

DÍAZ DE ZAPPIA, Sandra. Participación indígena en el gobierno de las reducciones jesuíticas de guaraníes. Revista de Historia del Derecho, v. 31, p. 97-129, 2003.

DRENNAN, Robert; URIBE, Carlos. Chiefdoms in the Americas. Lanham: University Press of America, 1987.

FAUSTO, Carlos. Fragmentos de história e cultura Tupinambá. Da etnologia como instrumento crítico de conhecimento etno-histórico. História dos índios no Brasil. CARNEIRO DA CUNHA, Manuela (Org.). São Paulo: Companhia das Letras, 1992.

FEINBERG, Richard; WATSON-GEGEO, Karen Ann (Eds.). Leadership and change in the Western Pacific: essays presented to Sir Raymond Firth on the occasion of his ninetienth birthday. London: The Athlone Press, 1996.

FERGUSON, R. Brian; WHITEHEAD, Neil L. (Eds.). War in the tribal rone. Expanding states and indigenous warfare. Sante Fe (EE.UU.): School of American Research Press, 1992.

GARCIA, Elisa Frühauf. As diversas formas de ser indio. Políticas indígenas e políticas indigenistas no extremo sul da América portuguesa. Rio de Janeiro: Arquivo Nacional, 2009. GIUDICELLI, Christophe (Ed.). Fronteras movedizas. Clasificaciones coloniales y dinámicas socioculturales en las fornteras americanas. México: Centro de Estudios Mexicanos y centroamericanos (CEMCA)-Colegio de Michoacán, 2010.

GLUCKMAN, Max. Analysis of a Social Situation in Modern Zululand. Manchester. Manchester University Press, 1940-1942.

GODELIER, Maurice; STRATHERN, Marilyn (Eds.). Big Men and Great Men. Cambridge: Cambridge University Press, 1991.

GONZÁLEZ, Julio Cesar. Notas para una historia de los treinta pueblos de Misiones. Parte I: El proceso de expulsión de los jesuitas (1768). Anuario de la Sociedad de Historia Argentina. v. IV, Buenos Aires, p. 273-347, 1942.

Anos 90, Porto Alegre, v. 18, n. 34, p. 19-54, dez. 2011 
GRUZINSKI, Serge. Elpensamiento mestizo. Buenos Aires: Paidós. 1999.

HAAS, Jonathan (Ed.). From Leaders to Rulers. New York: Kluwer Academic/ Plenum Publishers, 2001.

HILL, Jonathan D. History, power, and identity: ethnogenesis in the Americas, 14921992. Iowa City: University of Iowa Press, 1996.

JOHNSON, Allen W.; EARLE, Timothy. The evolution of Human Societies. From Foraging group to agrarian state. Stanford: Stanford Universty Press, 2000.

KRACKE, Waud. Force and Persuasion. Leadership in an Amazonian society. Chicago: The University of Chicago Press, 1978.

KRACKE, Waud (Ed.). Leadership in Lowland South America. South American Indian Studies 1. 1993.

LABOUGLE, Raul de. Litigios de Antaño. Buenos Aires: Ed. Coni, 1941.

LLOBERA, Josep (Comp.). Antropología politica. Barcelona: Anagrama, 1985.

MAEDER, Ernesto. La población de las Misiones de guaraníes (1641-1682) Reubicación de los pueblos y consecuencias demográficas. In: Estudos Iberoamericanos v. 15 , n. 1, p. 49-68, 1989.

MELIÀ, Bartomeu. La lengua guarani en el Paraguay colonial La creación de un lenguaje cristiano en las reducciones de los guaranies en el Paraguay. Asunción: CEPAG, 2003.

MORINIGO, Marcos Augusto. Raízy destino del guaraní. Asunción: CEADUC, 1990.

NECKER, Louis. Indios guaranies y chamanes franciscanos. Las primeras reducciones del Paraguay (1580-1800). Asunción: CEADUC, 1990.

NEUMANN, Eduardo. A escrita dos guaranis nas reduções: usos e funções das formas textuais indígenas. Século XVIII. Topoi v. 8, n. 15, p. 48-79, 2007.

. Escribiendo en la frontera del Paraguay: prácticas de la escritura guaraní durante la demarcación de límites (siglo XVIII). Cultura Escrita \& Sociedad n.7, p. 159-190, 2008.

. Razón gráfica y escritura indígena en las reducciones guaraníticas. Saberes de la conversión. Jesuitas, indígenas e imperios coloniales en las fronteras de la cristiandad. Wilde, G. (Comp.). p. 99-130. Buenos Aires: Editorial SB, 2011.

NUSDORFFER, Bernardo [c. 1755] 1969 Relacion de todo lo sucedido en estas Doctrinas en orden a las mudanzas de los 7 Pueblos del Uruguai desde S. Borja hasta S. Miguel inclusive, que por el tratado Real, y linea divisoria de los limites entre las dos Coronas, o se avian de entregar a los Portugueses, o se avian de mudar a otros parajes. Setembro de 1750 a fins de 1755. In: Manuscritos da Colecao de Angelils VII (1750-1802).

Anos 90, Porto Alegre, v. 18, n. 34, p. 19-54, dez. 2011 


\section{Guillermo Wilde}

PACHECO DE OLIVEIRA, João. Uma etnologia dos "indios Misturados"? Situação colonial, territorialização e fluxos culturais. Mana v. 4, n. 1, p. 47-77, 1998.

REVEL, Jacques. Micro-análisis y contrucción de lo social. Anuario del Instituto de Estudios Históricos y Sociales, 10, p. 125-143. Universidad Nacional del Centro de la Provincia de Buenos Aires, 1995.

RUIZ DE MONTOYA, Antonio. La Conquista espiritual del Paraguay. Rosario. Equipo Difusor de Estudios de Historia Iberoamericana. [1639] 1989.

SAHLINS, Marshall. Hombre pobre, hombre rico, gran hombre, jefe: Tipos políticos en Melanesia y polinesia. In: LLOBERA, Josep (Comp.). Antropología política, p. 267-288. Barcelona: Anagrama, 1985.

SAITO, Akira. ¿Quiénes son los Mojos? Un proceso de etnogénesis misional en el Alto Amazonas. Coloquio Internacional Tradiciones indígenas y Culturas misionales en las fornteras de Sudamérica colonial. Hacia una perspectiva comparativa. Buenos Aires, 16 y 17 de agosto de 2011. 2011.

SALINAS, María Laura. Liderazgos indígenas en las Misiones jesuíticas. Títulos de capitanes concedidos a los caciques guaraníes en el siglo XVII. Folia Histórica del Nordeste 16, p. 267-276. 2006.

SEVERI, Carlo. Capturing imagination: a cognitive approach to cultural complexity. Journal of the Royal Anthropological Institute (N.S.) v. 10, p. 815-838. 2004.

SIDER, Gerald. Identity as History. Ethnohistory, Ethnogenesis and Ethnocide in the Southeastern United States. Identities Global Studies in Culture and Power. New Hampshire, v. 1, 1994.

SWARTZ, Marc (Ed.). Local-level-politics. Chicago: Aldine, 1968.

[Sublevados] [10/1754] Cartas de Paracatú y Candiré. Daimán, octubre de 1754, ANCh (FJ) v. 200, pieza 11.

SUSNIK, Branislava. El Indio Colonial del Paraguay I: El Guarani colonial. Asunción. Museo Etnográfico “Andrés Barbero” (MEAB), 1965.

SUSNIK, Branislava; CHASE-SARDI, Miguel. Los indios del Paraguay. Madrid: MAPFRE, 1992.

SUSNIK, Branislava. Una visión socio-antropológica del Paraguay del siglo XV III. Asunción: MEAB, 1990-1991.

TAKEDA, Kazuhiza. ¿Continuidad u ocaso? Transformación del poder de los jefes étnicos en las misiones jesuíticas del Río de la Plata. Simposio Las reducciones indígenas: una visión comparativa. Lima, 6 y 7 de septiembre de 2010, Pontificia Universidad Católica del Perú, 2010. 
TAYUARÉ, Chrisanto [28-11-1769] Carta del cacique Christanto Tayuaré al gobernador, Yapeyú 28 de noviembre de 1769. AGN IX.18.5.1.

TURNER, Victor. Dramas, Fields and Metaphors. Symbolic Action in Human Society. Ithaca: Cornell University Press, 1974.

VILLAMARÍN, Juan; VILLAMARÍN, Judith. Chiefdoms: the prevalence and persistence of Señorís Naturales 1400 to European conquest. The Cambridge History of the Native Peoples of the Americas. Vol. III, Part 1: South America. SALOMON, Frank; SCHWARTZ, Stuart B. (Eds.). Cambridge: Cambridge University Press, 1999.

WHITE, Richard. The Middle Ground: Indians, empires and republics in the Great Lakes Region, 1650-1815. Cambridge: Cambridge University Press, 1991.

WILDE, Guillermo. Orden y ambigüedad en la formación territorial del Río de la Plata a fines del siglo XVIII. In: Horizontes Antropológicos, v. 19, p. 105-135, 2003a.

- Guaraníes, gauchos e indios infieles en el proceso de disgregación de las antiguas doctrinas jesuíticas del Paraguay. Suplemento Antropológico XXXVIII n. 2 , p. $73-130,2003$ b.

. Poderes del ritual y rituales del poder: un análisis de las celebraciones en los pueblos jesuíticos de guaraníes. Revista Española de Antropología Americana 33: p. 203-229, 2003c.

. Hacia una perspectiva situacional en el análisis del liderazgo indígena. Reflexiones a partir de los “Guaraníes históricos”. Historia, poder y discursos: p. 77-102. WILDE, G.; SCHAMBER, P. 2005 (Comp.). Buenos Aires: Editorial SB, 2005.

- Prestigio indígena y nobleza peninsular: la invención de linajes guaraníes en las Misiones del Paraguay. In: Jahrbuch für Gechichte Lateinamerikas 43: p. 119-145, 2006.

. Territorio y Etnogénesis misional en el Paraguay del siglo XVIII. In: Fronteiras, Revista de História, v. 11, n. 19, p. 83-106, 2009a.

. Religión y Poder en las Misiones de Guaranies. Buenos Aires: Editorial SB. 2009b.

. De las crónicas jesuíticas a las etnografías estatales: realidades y ficciones del orden misional en las fronteras Ibéricas. Nuevo Mundo Mundos Nuevos, Debates [En línea]. Disponible en: <http://nuevomundo.revues.org/62238>. Acesso em: 23 dici. 2011.

YEGUACÁ, Miguel. Carta al gobernador Bucareli. Pueblo de La Cruz, 22 de Septiembre de 1768. AGN IX.6.10.7. [22-9-1768].

Recebido em: 07/03/2012.

Aprovado em: 28/04/2012. 